\title{
Variable effects of termite mounds on African savanna grass communities across a rainfall gradient
}

\author{
Andrew B. Davies, Mark P. Robertson, Shaun R. Levick, Gregory P. Asner, Berndt J. van \\ Rensburg \& Catherine L. Parr
}

Davies, A.B. (Corresponding author, abdavies@zoology.up.ac.za), Robertson, M.P. (mrobertson@zoology.up.ac.za) \& van Rensburg, B.J. (b.vanrensburg@uq.edu.au): Centre for Invasion Biology, Department of Zoology and Entomology, University of Pretoria, Pretoria, 0002, South Africa Levick, S.R. (slevick@bgc-jena.mpg.de): Max Planck Institute for Biogeochemistry, Hans-Knöll Street 10, Jena, 07745, Germany

Asner, G.P. (gpa@stanford.edu): Department of Global Ecology, Carnegie Institution for Science, 260 Panama Street, Stanford, CA, USA

van Rensburg, B.J.: School of Biological Sciences, University of Queensland, St. Lucia, QLD 4072, Australia Parr, C.L. (Kate.Parr@liverpool.ac.uk): School of Environmental Sciences, University of Liverpool, Liverpool, L69 3GP, United Kingdom

Davies, A.B. present address: Department of Global Ecology, Carnegie Institution, 260 Panama Street, Stanford, CA, USA, adavies@ carnegiescience.edu

\begin{abstract}
Questions: Termite mounds of the genus Macrotermes are prominent features in African savannas, forming nutrient hotspots that support greater plant diversity, which is of higher nutritional value than the surrounding savanna matrix. However, little is known about grass communities on and around mounds or how the functional importance of mounds varies across sites. As mean annual rainfall increases, savannas in southern Africa become increasingly dystrophic through increased denitrification (including pyrodenitrification) and
\end{abstract}


the leaching of soil nutrients. The functional importance of mounds is concomitantly expected to increase as the difference in foliar nutrient levels between mounds and the savanna matrix increases. We tested this prediction on grass communities across a rainfall gradient i) to determine the degree to which grass assemblages differ between termite mounds and the savanna matrix, ii) to determine the spatial extent to which mounds influence grass communities, and iii) to investigate whether these patterns differ across savanna types. Location: Kruger National Park, South Africa

Methods: Grass communities were surveyed at three savanna sites differing in mean annual rainfall $\left(550-750 \mathrm{~mm} \cdot \mathrm{yr}^{-1}\right)$. Grass diversity and tissue nitrogen concentrations were measured on and off termite mounds and along transects away from mounds in order to calculate the spatial influence of termite mounds on savanna grass communities. Using termite mound densities estimated from airborne LiDAR, we upscaled field-based results to determine the percentage of the landscape influenced by Macrotermes termite activity. Results: Although species richness of grasses was lower on mounds than in the savanna matrix, the assemblage composition varied significantly, with higher nutrient concentrations in grasses located on mounds. This pattern became more distinct with increasing rainfall. The spatial extent of these nutrient-rich grasses also differed across the rainfall gradient, with a larger sphere of influence around mounds in wetter areas. Mounds distinctly altered grass communities over $\sim 2 \%$ of the entire landscape.

Conclusions: Our results show that Macrotermes mounds are important components of savanna heterogeneity, and reveal that the functional importance of mounds increases with increasing rainfall.

Keywords: LiDAR; Macrotermes; nutrients; spatial heterogeneity; species richness; vegetation 
Nomenclature: van Oudtshoorn (1999)

Running head: Grass communities and termite mounds

\section{Introduction}

Termites redistribute soil nutrients and can have profound influences on savanna vegetation (Dangerfield et al. 1998; Sileshi et al. 2010). The epigeal mounds constructed by some genera, such as Macrotermes, act as nutrient hotspots that have compositionally distinct plant communities on and around them. These community differences are attributed to a range of mechanisms including enhanced nutrient availability (Jouquet et al. 2005; Gosling et al. 2012) and moisture availability (Steinke \& Nel 1989; Erpenbach et al. 2013) as well as increased fire protection (Joseph et al. 2013b; Van der Plas et al. 2013). Once distinct communities have been established, positive feedback loops resulting from increased shading (Erpenbach et al. 2013; Van der Plas et al. 2013) and herbivory (Okullo \& Moe 2012a) further enhance and maintain differences.

While several studies have documented increased plant diversity on termite mounds (Loveridge \& Moe 2004; Traoré et al. 2008; Moe et al. 2009; Okullo \& Moe 2012b; Erpenbach et al. 2013; Joseph et al. 2013a), the majority of these have focused on woody plants. Studies explicitly documenting grass patterns have reported a range of responses including no differences between mounds and the savanna matrix in terms of species richness (Moe et al. 2009; Okullo \& Moe 2012a), a decrease in grass density on mounds (Jouquet et al. 2004) and distinct species assemblages on and off mounds (Spain \& McIvor 1988; Jouquet et al. 2004). However, studies considering grass diversity in its entirety (i.e. species richness, abundance (tuft density or cover) and species assemblage composition) are lacking. This despite grasses being a dominant and characteristic plant growth form in savannas, 
supporting abundant and diverse communities of grazing animals (du Toit \& Cumming 1999) and playing an important role in fire dynamics, an important component of savanna ecosystems (Bond \& Keeley 2005).

Virtually all previous studies have focused on single sites and have only considered local effects on vegetation. How the ecological effects of termite mounds may change across different savanna types remains unclear. In the only climatic gradient study we know of, Erpenbach et al. (2013) investigated vegetation patterns on and off Macrotermes mounds across a climatic gradient in west Africa, considering both woody and herbaceous vegetation. Differences between mounds and the savanna matrix became more pronounced with increasing mean annual precipitation, attributed to increased phytodiversity in wetter habitats. However, when considering herbaceous plants, grass and forb species were pooled, making grass patterns indistinguishable from other herbaceous vegetation (i.e. forbs). Furthermore, a recent study by van der Plas et al. (2013) found that browsing herbivores avoided Macrotermes mound vegetation in South Africa's Hluhluwe-iMfolozi Game Reserve. This result stands in contrast to previous work that documented preferential browsing of mound vegetation (e.g. Holdo \& McDowell 2004; Loveridge \& Moe 2004; Mobæk et al. 2005; Brody et al. 2010; Levick et al. 2010b). This unique finding was attributed to higher soil nutrients in the savanna matrix of the study site relative to other savanna areas, resulting in little nutritional difference between mound and savanna matrix vegetation. These studies imply that termite mounds do not enhance savanna vegetation heterogeneity in the same way across all habitats with more across-site studies necessary before general conclusions can be drawn.

In addition to variation in the degree of difference between mound and savanna matrix vegetation across savanna sites, it is also likely that the sphere of influence around termite mounds (i.e., the area that mounds influence) will vary across sites. Most studies have 
only assessed patterns on and off mounds, with limited information available on the extent of mound influence. As a result, the ecological effects of termite mounds and the spatial extent of such effects are poorly quantified at landscape scales (Levick et al. 2010b; Sileshi \& Arshad 2012).

We investigated effects of Macrotermes mounds on grass assemblages across distinct savanna types differing in mean annual precipitation and vegetation communities. We further quantified the sphere of influence around mounds and scaled these findings up to the landscape level, thereby uncovering how the overall influence of mounds on ecological processes varies across savanna habitats. The aims of the study were: i) to determine the degree to which grass assemblages (species richness, grass cover (abundance) and community assemblages) differ between termite mounds and the savanna matrix, ii) to determine the spatial extent (sphere of influence) to which mounds influence grass communities, both locally around mounds and at a landscape scale, including whether there is a gradual change in grass assemblages from mound to savanna matrix or if clear thresholds of change can be detected, and iii) to investigate whether these patterns differ across savanna types from relatively dry $\left(550 \mathrm{~mm} \cdot \mathrm{yr}^{-1}\right)$ to relatively wet $\left(750 \mathrm{~mm} \cdot \mathrm{yr}^{-1}\right)$ savanna. We predicted that effects of mounds, including both the degree of difference in grass communities and the spatial extent of their influence, would be strongest in wetter savannas where foliar (grass) nutrients were expected to differ most between mounds and the savanna matrix. This because the increased phytodiversity on termite mounds is strongly linked to enhanced soil nutrition (Joseph et al. 2013a; Seymour et al. 2014), therefore where grasses of higher nutrient content are able to persist in the savanna matrix (drier savannas), effects of mounds on grass assemblages are expected to be lower, including the extent of spatial effects because high nutrient grasses will not be dependent on mounds. 


\section{Methods}

Study site

The study took place in three savanna vegetation types along a rainfall gradient in southern Kruger National Park, South Africa. These three sites occur in a summer rainfall region and vary in mean annual precipitation and vegetation characteristics. Due to processes such as increased denitrification (including pyrodenitrification) and soil leaching, wetter savannas in southern Africa are generally nutrient-poor compared to drier ones (Scholes 1997). The vegetation at the driest site (Skukuza) is relatively nutrient-rich savanna (sweet veld) and characterised by an Acacia nigrescens/Combretum apiculatum association and receives a mean rainfall of $550 \mathrm{~mm} \cdot \mathrm{yr}^{-1}$. The wettest site (Pretoriuskop) is dominated by Terminalia sericea and Dichrostachys cinerea and has comparatively nutrient-poor vegetation (sour veld); mean annual rainfall here is $750 \mathrm{~mm} \cdot \mathrm{yr}^{-1}$. An intermediate site (Napi) is located between these two distinct regions and contains a mosaic of the two vegetation types, with Combretum zeyheri and C. collinum being dominant tree species, rainfall here is also intermediate, ca. $625 \mathrm{~mm} . \mathrm{yr}^{-1}$ (Gertenbach 1983). Herbivore biomass varied across the three sites, with the highest levels recorded at the intermediate site (Napi, $3490.36 \mathrm{~kg} / \mathrm{km}^{2}$ ), followed by the driest (Skukuza, $1568.24 \mathrm{~kg} / \mathrm{km}^{2}$ ) and finally the wettest site (Pretoriuskop, $838.20 \mathrm{~kg} / \mathrm{km}^{2}$ ). All three sites occur within an undulating landscape on granitic substrate; Macrotermes mounds occur predominantly on crests and upper sections of hillslopes (Levick et al. 2010a; Davies et al. 2014).

\section{Study design}

Within each savanna site, areas of relatively high ( $\geq \sim 1$ mound.ha ${ }^{-1}$, see Davies et al. 2014) Macrotermes mound densities were selected using Light Detection and Ranging (LiDAR) data from the Carnegie Airborne Observatory Alpha sensor package (CAO-Alpha; Asner et 
al. 2007). Ten termite mounds spaced at least $50 \mathrm{~m}$ apart (and in most cases over $100 \mathrm{~m}$ apart) were then selected within three sites across the rainfall gradient and surveyed during January 2012, the peak summer month when grasses are abundant and identifiable. All surveyed termite mounds were built by Macrotermes, with the dominant species in the area being M. falciger and M. natalensis (Davies et al. 2014). Both active and inactive mounds are vegetated in this region so we did not discriminate between these two classes. Mound diameter was measured for each mound along the north-south and east-west axes and the average diameter calculated from these measurements.

The grass communities on and around each mound were surveyed using $1 \mathrm{~m}^{2}$ quadrats. Sixteen quadrats were placed on the termite mound, six on the upper sections and ten on the lower sections, where more surface area was available. Each grass species present in the quadrat was identified and the percentage of the quadrat that it occupied (basal cover) visually estimated. Sampling quadrats were stratified according to aspect, with half (eight) on the northern section of the mound and the other half on the southern section. For each termite mound, a paired savanna plot situated $30 \mathrm{~m}$ from the edge of the mound was also sampled. A random direction for the placement of the savanna plot was chosen each time and this plot was placed at least $30 \mathrm{~m}$ away from any neighbouring mounds. At this savanna plot, 16 quadrats were placed in a grid formation of 4 by 4 , spaced one meter apart. Finally, transects were laid out from each mound in the four cardinal directions. A total of six quadrats were placed at the following distance intervals from the base of the mound along each transect: 1 m, $2 \mathrm{~m}, 4 \mathrm{~m}, 8 \mathrm{~m}, 16 \mathrm{~m}$ and $32 \mathrm{~m}$ (Appendix S1). Changes in vegetation composition were expected to be most pronounced closer to mounds; hence a geometric progression with the common ratio of 2 was selected. In each quadrat (on the mounds, savanna plots and transects) standing biomass readings were recorded using a disc pasture meter. The disc pasture meter 
has been calibrated for this vegetation type and biomass was calculated with the following formula from Trollope (1990):

$(\sqrt{ } X \times 2260)-3019=\mathrm{kg} \mathrm{ha}^{-1}$

where $X$ is the disc height reading in $\mathrm{cm}$ obtained from the disc pasture meter.

\section{Nutrient sampling}

Grass samples collected from the termite mounds and each quadrat along transects were harvested for analysis of nitrogen and carbon content. Grass samples were representative of all species present in each quadrat, and the amount of each species harvested was in proportion to its abundance in the quadrat. All samples consisted of above-ground plant material. Samples were dried at $60^{\circ} \mathrm{C}$ for $48 \mathrm{hr}$ immediately after collection, following which they were homogenised. Total $\mathrm{C}$ and $\mathrm{N}$ concentrations of ground grass material were analysed using an elemental analyser "Vario EL" (Elementar Analysensysteme GmbH, Hanau, Germany) at the Max Planck Institute for Biogeochemistry, Jena, Germany.

\section{Analysis}

Sampling adequacy of the grass surveyed on termite mounds and savanna plots was assessed using sample-based rarefaction curves and appropriate richness estimators (Gotelli \& Colwell 2001) using EstimateS software version 8.2 (http://viceroy.eeb.uconn.edu/estimates). In almost all cases, sampling was considered adequate and so observed data were used in subsequent analyses (see Appendix S2 for more information and results).

Grass species richness, basal grass cover (percentage of the quadrat occupied by grass) and standing biomass on and off termite mounds was compared using two-way analysis of variance (ANOVA), after data were assessed for normality and homogeneity of 
variance. An arcsine square root transformation was applied to all percentage (basal grass cover) data before analysis. For multivariate community assemblage analyses, data were double square-root transformed to weight common and rare species more equally (Clarke \& Warwick 2001), following which a Bray-Curtis dissimilarity matrix was constructed. Overall differences in grass community assemblages on and off mounds were compared using a twoway analysis of similarity (ANOSIM) with pair-wise comparisons made between sites. Oneway ANOSIMs were used to compare treatment (mound vs. savanna) assemblages at each site separately. The $R$-value obtained from ANOSIM is a measure of dissimilarity and can take a value between -1 and 1 , the closer this value is to 1 the more dissimilar the assemblages are (Clarke \& Warwick 2001). Non-metric multi-dimensional scaling (nMDS) ordinations for each savanna site were constructed to visually display patterns.

Individual grass species indicative of termite mounds were identified for each savanna habitat using the Indicator Value (IndVal) method (Dufrêne \& Legendre 1997). This method uses a combination of site specificity (uniqueness to a particular habitat) and fidelity (frequency of occurrence within that habitat) to assess the extent to which a species is indicative of that site. A high indicator value, expressed as a percentage, signifies that a species is characteristic of a specific site (Dufrêne \& Legendre 1997). Species that scored significant IndVal values greater than $60 \%$ were subjectively considered characteristic of that habitat (modified from McGeoch et al. 2002). Although the method was originally designed to detect species indicative of specific habitats, in this context it was used to test if there are specific grass species associated with termite mounds and if such characteristic species change across the rainfall gradient.

Data collected from the distance transects were pooled across the four directions and grass species richness, grass basal cover (arcsine square root transformed) and standing biomass were compared across distance classes and sites using two-way ANOVAs. Grass 
assemblage composition was analysed in a similar fashion to those on and off mounds, with the use of ANOSIMs and nMDS ordinations. In order to detect changes in assemblages with distance relative to mounds and to identify where such changes become apparent, ANOSIM was used to compare grass assemblages at each distance category (pooled across directions) to assemblages on the mound. Further, we used Mantel's test to construct Mantel correlograms to calculate patterns of spatial autocorrelation. The Mantel test can be used to examine relationships between multivariate dissimilarity matrices and a matrix of their geographic positions and determines spatial dependence at different distance classes (Borcard et al. 2011). The correlogram produces $r$ coefficients between -1 and 1 , where 1 is completely spatially dependent and -1 spatially independent. Mantel correlograms conduct pair-wise tests with a Holm correction for multiple comparisons for each distance class. A Bray-Cutis dissimilarity matrix was constructed from the assemblage data (after an arcsine transformation was applied) and detrended by regression on the site coordinates before Mantel correlograms were constructed (Borcard et al. 2011). For these correlograms, data were pooled across the ten mounds per site, but directional data were not pooled in order to increase statistical power.

The C: $\mathrm{N}$ ratio was calculated from the tissue samples. The data were log transformed to meet assumptions of normality and homogeneity of variance and changes in the $\mathrm{C}: \mathrm{N}$ ratio along the transects assessed with two-way ANOVA. The ANOSIM and nMDS analyses were performed using Primer software version 5.2 (Clarke \& Warwick 2001), while all other analyses were conducted with R software version 2.15.1 (R Development Core Team 2012), the R package vegan was used for the Mantel correlograms and the package labdsv for the IndVal analyses.

To determine the sphere of influence of mounds on grass assemblage composition in each study site, the mean mound diameter was calculated and added to the extent of direct 
influence determined from the distance transects to obtain a radius of influence from the centre of a termite mound. This sphere of influence was assumed to be circular, and the area under direct influence of a termite mound calculated. For these calculations, the influence on grass community composition was used instead of species richness, basal cover or standing biomass because these patterns were the clearest and are more meaningful for savanna heterogeneity as mounds have more effect on grass assemblages than the other variables measured (see Results). Using LiDAR terrain data from the Carnegie Airborne Observatory (CAO, http:cao.ciw.edu), mound densities on crests in each study area were estimated and a correction factor applied to account for variation in detection rates across the study site (see Davies et al. 2014). The area that is directly influenced by mounds was then calculated for each study site. Crests were chosen instead of the entire landscape because Macrotermes mounds occur predominantly on them (Levick et al. 2010a; Davies et al. 2014) and therefore will be influential in these areas. Due to the nature of the remote sensing technique used, some small mounds $(<0.5 \mathrm{~m}$ height) escaped detection and these estimations can thus be considered minimum values.

\section{Results}

Grass assemblages on and off termite mounds

Grass species richness varied significantly across the three savanna sites (two-way ANOVA, $\mathrm{F}=6.988, \mathrm{p}<0.01$, Fig. 1a), and there were significantly more species off mounds than on mounds (two-way ANOVA, $F=72.123, \mathrm{p}<0.001$, Fig. 1a). The interaction between these two factors was not significant (two-way ANOVA, $F=0.239, \mathrm{p}=0.788$ ), indicating that the effect was similar across all three sites. A Tukey Honest Significant Difference (Tukey HSD) test showed that between sites, Skukuza (the driest site) had significantly more species than both Napi (intermediate) and Pretoriuskop (wettest site) ( $\mathrm{p}<0.01$ and $<0.05$ respectively), 
a)

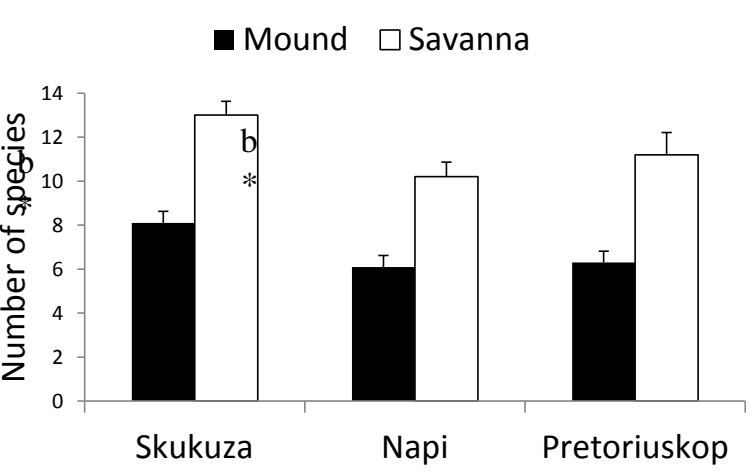

b)

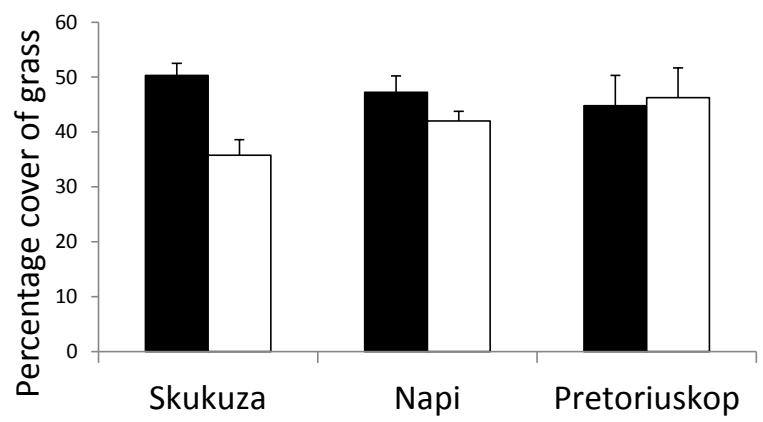

c)

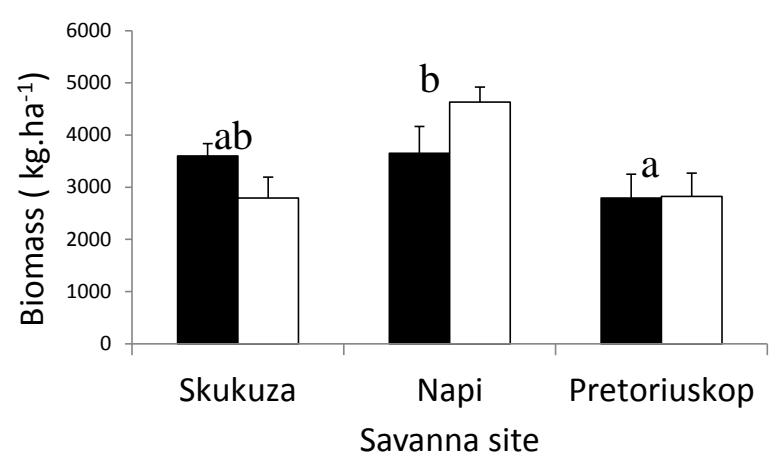

Figure 1: Grass species richness (a), percentage basal grass cover (b), and standing biomass of grass (c) on and off Macrotermes mounds at three savanna sites across a rainfall gradient. Sites are arranged in order of increasing mean annual rainfall. Letters indicate differences between savanna sites while asterisks denote significant differences between treatments (mounds $v s$. savanna).

which did not differ from each other $(\mathrm{p}=0.644)$. Across the rainfall gradient, grass species richness on mounds did not differ, i.e. mounds in all three areas had similar species richness (Fig. 1a). Among the savanna matrix plots, only Skukuza had significantly more species than Napi ( $<$ 0.05), but a similar number to Pretoriuskop (Fig. 1a). When comparing species richness on and off termite mounds, savanna matrix plots contained more species at every site ( $\mathrm{p}<0.001$ for all three sites, Fig. 1a). 
Grass cover did not differ significantly between sites (two-way ANOVA, $F=0.218, p$ $=0.805)$ nor between mound and savanna plots, although this comparison did approach significance: two-way ANOVA, $F=3.982, \mathrm{p}=0.051$, most notably at the driest site (Skukuza) where more cover was found on mounds than in the savanna matrix (Fig. 1b). The interaction between site and treatment was not significant (two-way ANOVA, F $=2.306, \mathrm{p}=$ 0.109). Standing biomass varied significantly across sites (being highest at the intermediate site (Napi), two-way ANOVA, $\mathrm{F}=5.817, \mathrm{p}<0.01$ ). Biomass was significantly higher at Napi than the wettest site (Pretoriuskop) ( $p<0.01)$, but not between other sites. No biomass differences were recorded between mound and savanna plots (two-way ANOVA, F $=0.045$, $\mathrm{p}=0.834$, Fig. 1c)

Grass community assemblages differed significantly between mounds and savanna plots at all three sites with little overlap of species (Table 1, Fig. 2, Appendix S3). Between sites, Skukuza and Napi had the most similar assemblages, while Pretoriuskop had a markedly different assemblage (Table 1, Fig. 2).

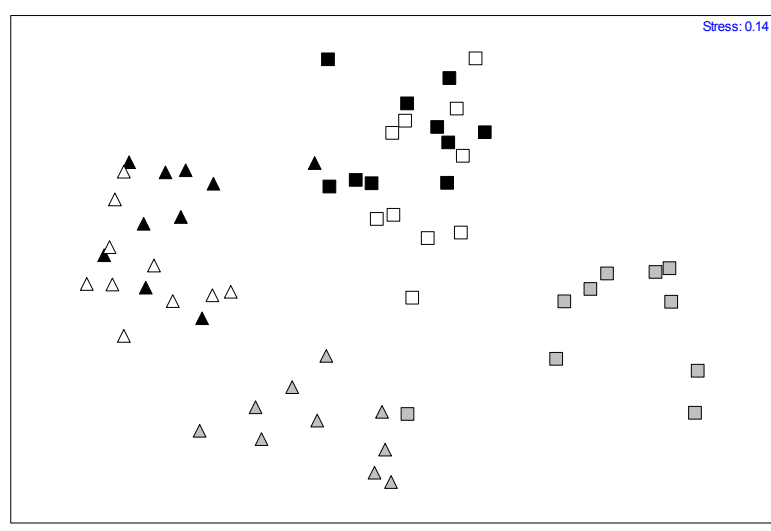

$\mathbf{\Delta}=$ termite mounds at Skukuza; $\bigwedge=$ termite mounds at Napi; $\Delta=$ termite mounds at Pretoriuskop; $\mathbf{\square}=$ savanna plots at Skukuza; $\square=$ savanna plots at Napi; $\_$= savanna plots at Pretoriuskop

Figure 2: Non-metric multi-dimensional scaling (nMDS) ordination of grass assemblages occurring on and off termite mounds at three savanna sites. 
Table 1: Results from an analysis of similarity (ANOSIM) of grass assemblages between termite mounds and savanna plots as well as between the three research sites (mound and matrix vegetation pooled). A two-way crossed ANOSIM was performed for overall treatment differences (averaged across all sites) and site differences (including pair-wise comparisons), while a one-way ANOSIM was performed for treatment effects at each savanna site separately. The R-statistic is a measure of similarity of assemblages, the closer this value is to 1 , the more dissimilar assemblages are. Sites are arranged in order of increasing rainfall. Sites are arranged in order of increasing mean annual precipitation; Skukuza receives $550 \mathrm{~mm} \cdot \mathrm{yr}^{-1}$, Napi $625 \mathrm{~mm} \cdot \mathrm{yr}^{-1}$ and Pretoriuskop 750 $\mathrm{mm} \cdot \mathrm{yr}^{-1}$.

\begin{tabular}{|c|c|c|c|c|}
\hline Factor & & R statistic & & $P$ value \\
\hline Treatment (overall) & & 0.900 & & 0.001 \\
\hline Skukuza & 0.823 & & 0.001 & \\
\hline Napi & & 0.982 & & 0.001 \\
\hline Pretoriuskop & & 0.886 & & 0.001 \\
\hline Site & & 0.710 & & 0.001 \\
\hline Skukuza vs. Napi & 0.313 & & 0.001 & \\
\hline Skukuza vs. Pretoriuskop & 0.905 & & 0.001 & \\
\hline Napi vs. Pretoriuskop & & 0.894 & & 0.001 \\
\hline
\end{tabular}

Seven grass species were identified as characteristic of termite mounds (Table 2). More indicator species were identified with increasing site precipitation (four species at Pretoriuskop, three at Napi and two at Skukuza) with a perfect indicator (Cynodon dactylon) identified at Pretoriuskop. One species (Urochloa mosambicensis) was characteristic of termite mounds at all three sites. 
Table 2: Species identified as characteristic of termite mounds for each research site arranged along a climatic gradient from dry to wet. Significant indicator values above $60 \%$ are shown $(100 \%$ being a perfect indicator, $\mathrm{P}<$ $0.05,1000$ iterations). * denotes a significant indicator but with an IndVal value <60\%; n.s. is present but not significant; - denotes that the species is absent from the site. Sites are arranged in order of increasing mean annual precipitation; Skukuza receives $550 \mathrm{~mm} \cdot \mathrm{yr}^{-1}$, Napi $625 \mathrm{~mm} . \mathrm{yr}^{-1}$ and Pretoriuskop $750 \mathrm{~mm} . \mathrm{yr}^{-1}$.

\begin{tabular}{|c|c|c|c|c|}
\hline \multirow[t]{2}{*}{ Species } & \multicolumn{3}{|c|}{ Site } & \multirow[b]{2}{*}{ Pretoriuskop } \\
\hline & & Skukuza Napi & & \\
\hline Cynodon dactylon & & - & - & 100.0 \\
\hline Urochloa mosambicensis & 89.48 & 77.66 & & 60.00 \\
\hline Panicum maximum & & n.s. & n.s. & 87.26 \\
\hline Bothriochloa radicans & $*$ & 70.00 & & - \\
\hline Brachiaria deflexa & & $*$ & 70.00 & - \\
\hline Eragrostis superba & & n.s. & n.s. & 65.97 \\
\hline Cenchrus ciliaris & 60.00 & n.s. & & - \\
\hline
\end{tabular}

\section{Grass assemblages across transects}

Species richness differed significantly along the distance transects (two-way ANOVA, F = 5.454, $\mathrm{p}<0.001$ ), with Tukey HSD tests revealing that mounds had significantly fewer species than $4 \mathrm{~m}$ and upwards $(\mathrm{p}<0.05)$. Furthermore, there were significantly more species at $32 \mathrm{~m}$ than at $1 \mathrm{~m}(\mathrm{p}<0.01)$ from mounds. Neither site nor an interaction between site and distance were significant, indicating that patterns were consistent across savanna sites (Appendix S4a).

Grass cover differed significantly between both site and distance category (two-way ANOVA, site: $\mathrm{F}=8.344, \mathrm{p}<0.001$; distance: $\mathrm{F}=3.101, \mathrm{p}<0.01)$, but the interaction between the two variables was not significant (two-way ANOVA, $\mathrm{F}=0.856, \mathrm{p}=0.593$ ). Tukey HSD tests showed that the wettest site, Pretoriuskop, had significantly greater grass cover than the driest site, Skukuza ( $\mathrm{p}<0.001)$, and there was a trend of more grass at Pretoriuskop compared to the intermediate site, Napi $(\mathrm{p}=0.09)$. No pairwise comparisons 
were significant between distance classes, but there was a trend toward less grass cover at intermediate distance classes ( 8 and $16 \mathrm{~m}$ ) compared to the edge of the mound (1 and $2 \mathrm{~m})$ (Appendix S4b).

For standing biomass, site, distance class and the interaction between the two differed significantly (two-way ANOVA, site: $\mathrm{F}=5.929, \mathrm{p}<0.01$; distance: $\mathrm{F}=2.325, \mathrm{p}<0.05$; interaction: $\mathrm{F}=1.806, \mathrm{p}<0.05)$. Napi had a significantly higher biomass than the other two sites $(\mathrm{p}<0.05$ for Pretoriuskop and $\mathrm{p}<0.01$ for Skukuza). Across distance classes, less biomass occurred at the $1 \mathrm{~m}$ distance category compared to the $4 \mathrm{~m}(\mathrm{p}=0.078), 8 \mathrm{~m}(\mathrm{p}<$ $0.05)$ and $32 \mathrm{~m}(\mathrm{p}=0.086)$ distances, these effects were most pronounced at the intermediate site (Napi), with considerably lower biomass at the $1 \mathrm{~m}$ distance class (Appendix S4c). Although grass cover and biomass results from the transects appear to contradict those recorded from on and off mounds, the transects represent data from several distance classes along the transect while the on and off mound comparisons are from only two locations. The transect data thus represent a continuum within which site differences occur. Both datasets were deemed necessary for analysis because a single quadrat $32 \mathrm{~m}$ from a mound was not considered to be an adequate representation of the savanna matrix compared to 16 quadrats sampled on each termite mound.

Differences in grass assemblage composition along transects varied across the rainfall gradient. At the driest site, Skukuza, a gradual change in grass composition from mound to matrix was observed, with no clear threshold at any one point (Fig. 3a). As mean annual rainfall increased, a clearer transition in grass composition was evident among distance categories, most notably from 2-4 m. This change was most pronounced at the wettest site, Pretoriuskop (Fig. 3b and c). Spatial turnover in grass communities was clear from both the nMDS ordinations and the R statistics from ANOSIM tests, which depict the magnitude of change in assemblages between the mound and a particular distance category (Fig. 3). Spatial 
a)
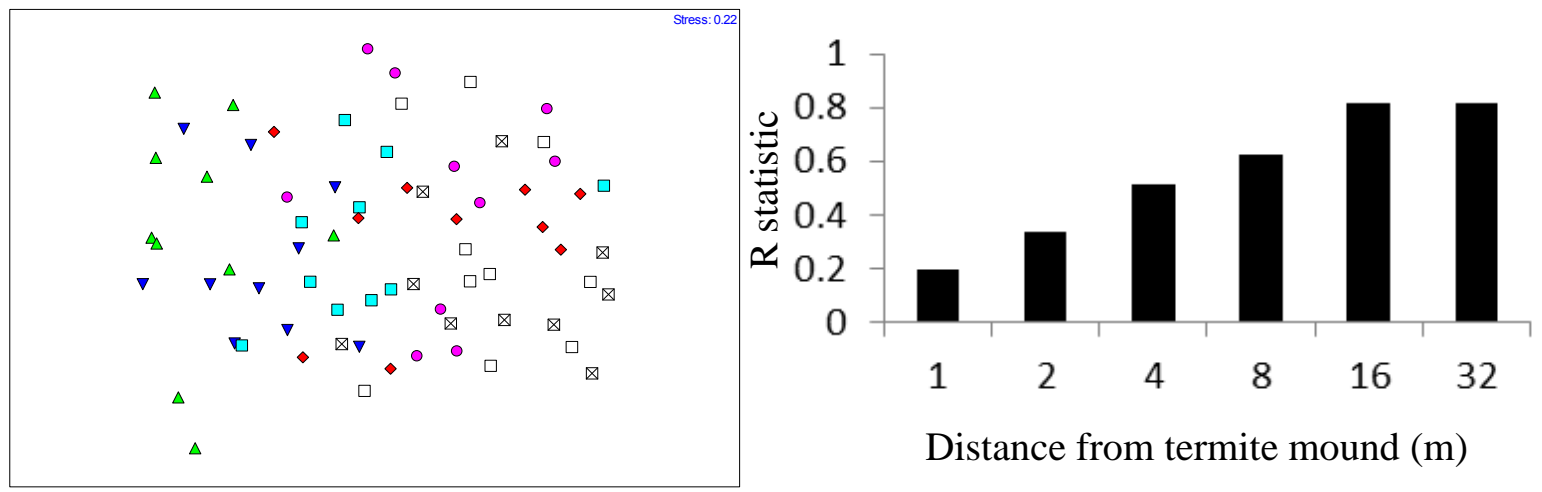

Distance from termite mound (m)

b)
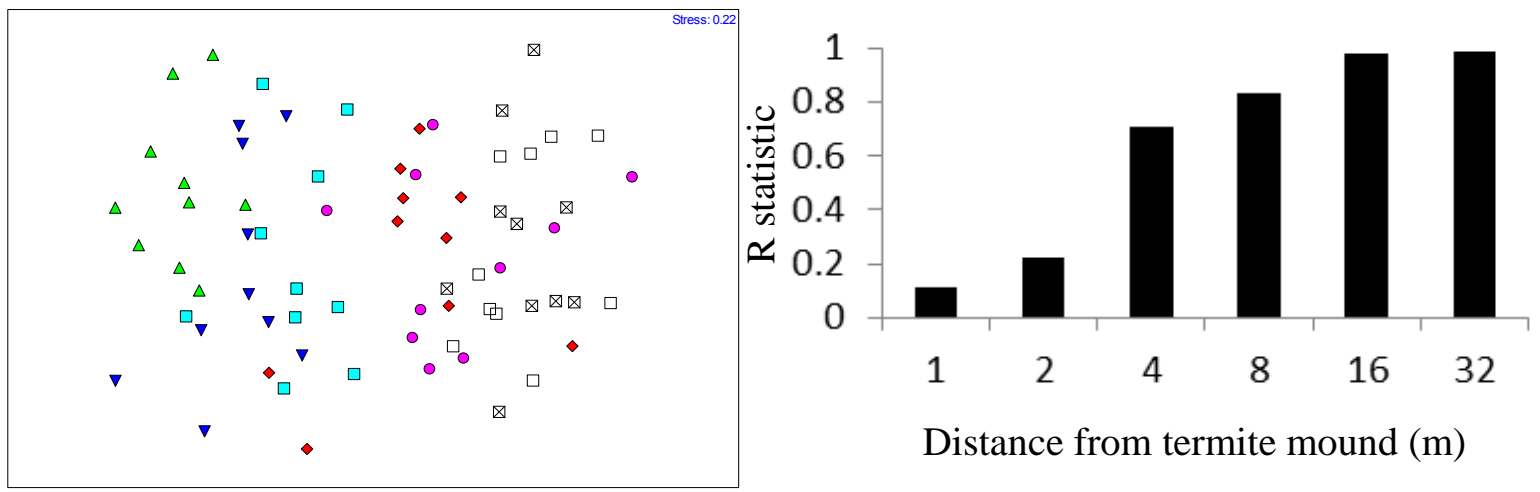

Distance from termite mound $(\mathrm{m})$

c)
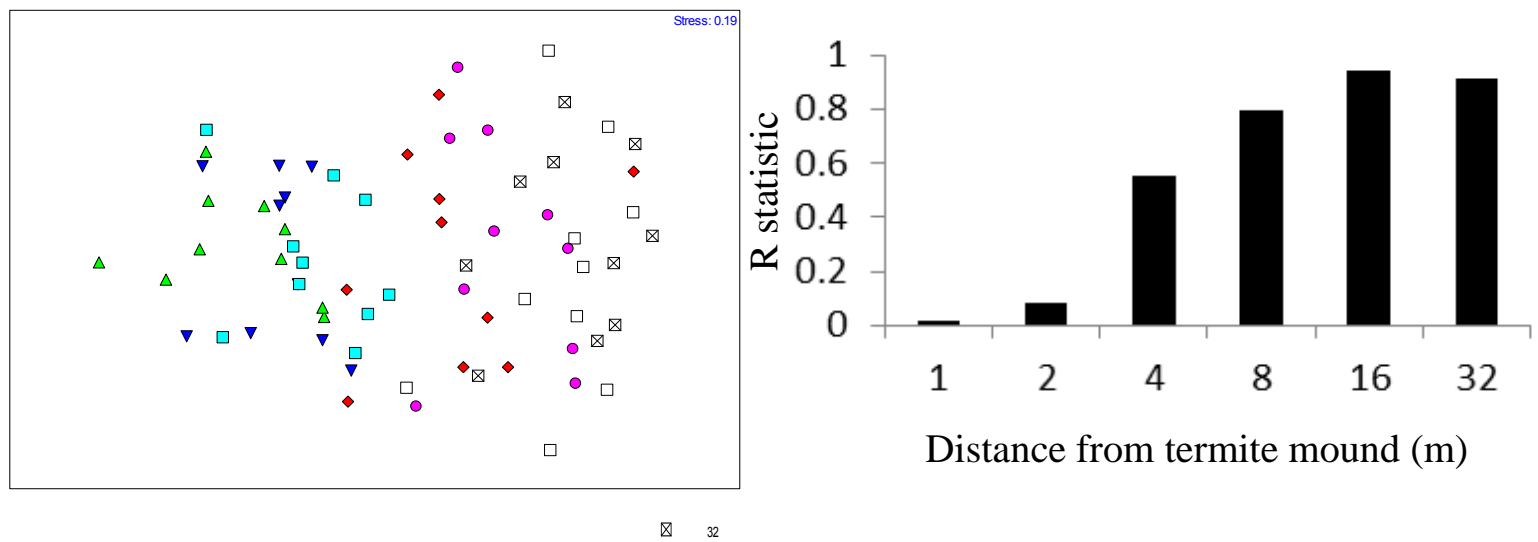

Distance from termite mound (m)

Figure 3: Non-metric multi-dimensional scaling (nMDS) ordinations of grass assemblages along transects of increasing distance from termite mounds at three savanna sites differing in mean annual rainfall, Skukuza (a), Napi (b) and Pretoriuskop (c). Ordinations are displayed on the left panel while the bar graphs in the right panel represent the size of the R statistic from an ANOSIM between assemblages on termite mounds and at various distances away from the mound. All R statistics were significant $(\mathrm{p}<0.05)$ at Skukuza, from 2 m upwards at Napi and from $4 \mathrm{~m}$ upwards at Pretoriuskop. 
a)

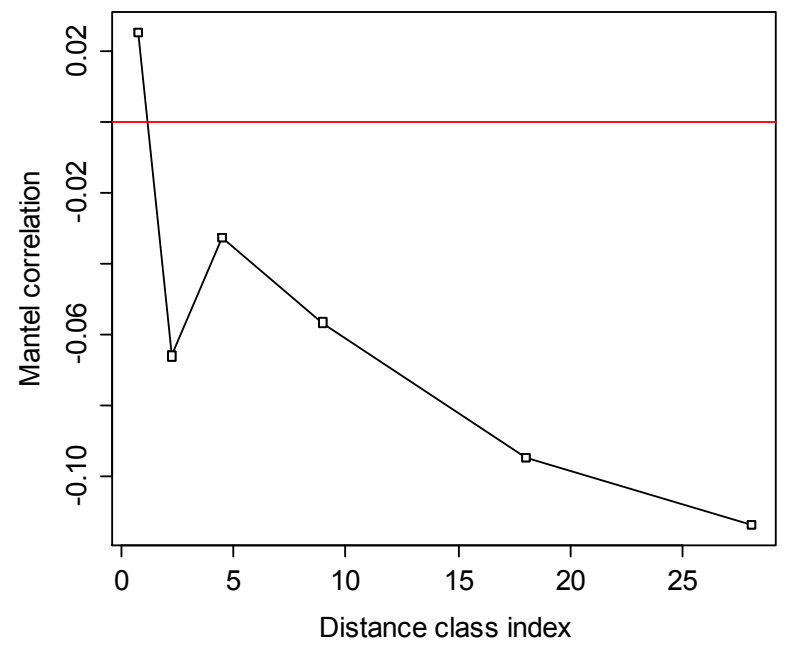

b)

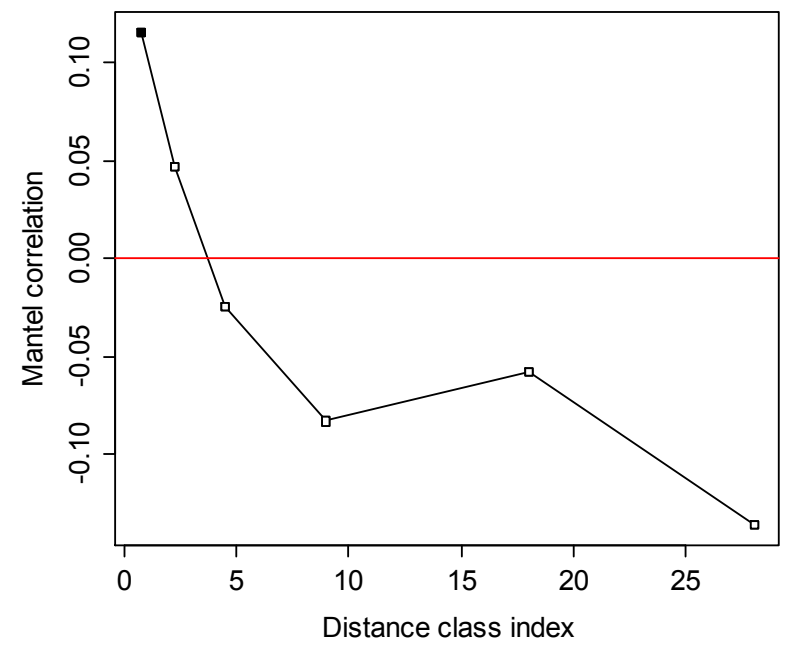

c)

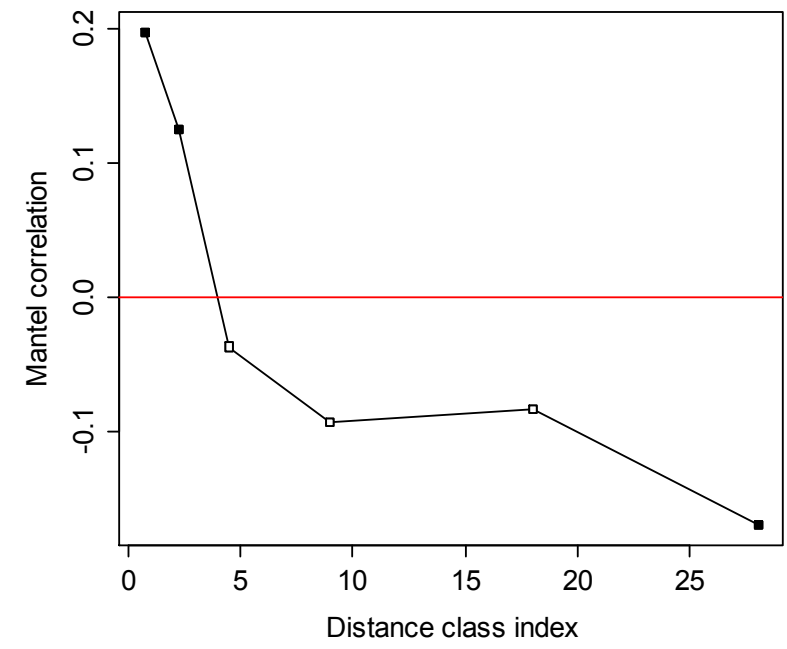

Figure 4: Spatial dependence of grass communities (Mantel Correlograms) surveyed around termite mounds at three savanna site across a rainfall gradient, the three site arranged in order of increasing mean annual precipitation are: a) Skukuza, b) Napi and c) Pretoriuskop. Black squares represent significant spatial auto-correlation ( $\alpha=0.05$ ); the line through zero indicates the transition from spatial dependence (above zero) to spatial independence (below zero); distance class index is measured in meters. 
autocorrelation analyses (Mantel correlograms) confirm the thresholds in grass composition across the rainfall gradient with a more gradual response at Skukuza, where no significant spatial dependence was detected (Fig. 4a). Spatial dependence persists further from mounds with increasing mean annual rainfall: grass community assemblages are significantly spatially dependent at $1 \mathrm{~m}$ distances at Napi (Fig. 4b) and up to $2 \mathrm{~m}$ at Pretoriuskop where they are also spatially independent at distances over 25 m (Fig. 4c). At both Napi and Pretoriuskop, assemblages are spatially independent and no longer positively correlated at $4 \mathrm{~m}$ from mounds.

\section{Foliar nutrients}

The spatial pattern of grass $\mathrm{C}: \mathrm{N}$ ratio mirrored the assemblage changes, with a clear increase recorded from the mound up until $2 \mathrm{~m}$ from the mound, followed by a levelling off at Skukuza. At both Napi and Pretoriuskop a steep increase was evident up until $4 \mathrm{~m}$ from the mound, with the $\mathrm{C}$ : $\mathrm{N}$ ratio only levelling off $16 \mathrm{~m}$ into the savanna matrix (Fig. 5). Two-way ANOVA confirmed that the $\mathrm{C}: \mathrm{N}$ ratio differed with site and distance, and the interaction between these two factors was significant (site: $F=33.348, p<0.001$; distance: $F=37.967$, $p$ $<0.001$; interaction: $\mathrm{F}=2.565, \mathrm{p}<0.01)$. Skukuza had a significantly lower $\mathrm{C}: \mathrm{N}$ ratio than both Napi (Tukey HSD, p < 0.001) and Pretoriuskop (Tukey HSD, p < 0.001), which did not differ from each other $(\mathrm{p}=0.081)$. The $\mathrm{C}: \mathrm{N}$ ratio increased significantly with distance from mounds, with all distance classes having a higher $\mathrm{C}: \mathrm{N}$ ratio than the mound $(\mathrm{p}<0.001$ for all pair-wise comparisons). Off the mound, distances of $4 \mathrm{~m}$ and upwards had significantly higher $\mathrm{C}$ : $\mathrm{N}$ ratio than $1 \mathrm{~m}$ from the mound ( $\mathrm{p}<0.001$ for all comparisons) and all distances greater than $8 \mathrm{~m}$ had a significantly higher $\mathrm{C}$ : $\mathrm{N}$ ratio than $2 \mathrm{~m}$ from mounds $(\mathrm{p}<0.01)$. Comparisons between the other classes $(4 \mathrm{~m}, 8 \mathrm{~m}, 16 \mathrm{~m}$ and $32 \mathrm{~m})$ did not differ significantly from each other, apart from between $4 \mathrm{~m}$ and $32 \mathrm{~m}(\mathrm{p}<0.05)$. Thus, the $\mathrm{C}$ : $\mathrm{N}$ ratio 
significantly increases up until $4 \mathrm{~m}$ from mounds, after which it increases only slightly to be higher at $32 \mathrm{~m}$ compared to $4 \mathrm{~m}$. The interaction term was significant, with stronger (steeper increases in $\mathrm{C}: \mathrm{N}$ ratio) responses observed with increasing rainfall, being highest at Pretoriuskop (Fig. 5).

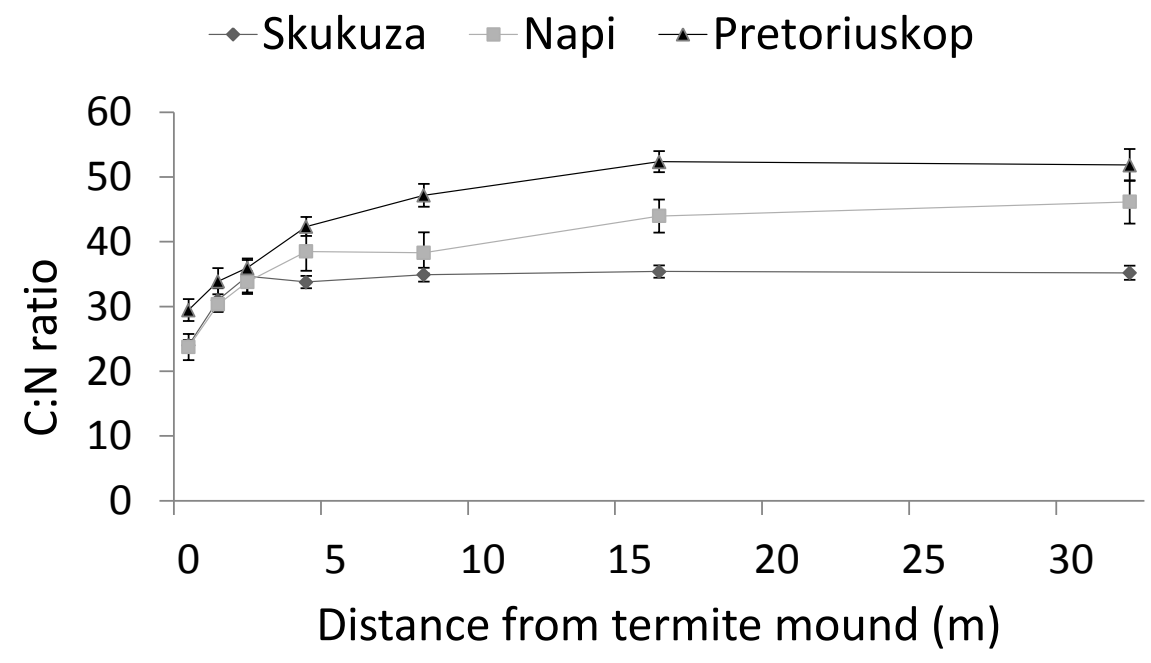

Figure 5: Carbon to Nitrogen $(\mathrm{C}: \mathrm{N})$ ratio for grass samples across distance transects from termite mounds. Samples were taken from the four cardinal directions around mounds.

\section{Sphere of influence around termite mounds}

The sphere of direct influence around mounds was determined for each study site using the magnitude of grass assemblage changes at various distance intervals from ANOSIM and nMDS results (Fig. 3), and the Mantel correlograms (Fig. 4). Considering these assemblage changes, a gradual compositional change was observed at the driest site (Skukuza) where, according to the ANOSIM, grass assemblage composition continues to change relative to the mound as far as $16 \mathrm{~m}$ into the savanna matrix, suggesting a gradual rather than an abrupt change. However, community differences beyond $2 \mathrm{~m}$ are not enough to garner support from the Mantel correlograms. Mound influence was therefore conservatively considered to extend to $2 \mathrm{~m}$, following which, differences in assemblages are less pronounced with increasing distance (Fig. 3a) and spatially independent (Fig. 4a). At Napi and especially Pretoriuskop 
(the wettest site), thresholds in community compositional change are easier to detect, with grass communities being distinctly different at a distance of $4 \mathrm{~m}$ into the savanna matrix at both sites (Fig. 3b and c and Fig. 4b and c). Based on this and the Mantel correlograms, mound influence at these sites was considered to extend to $4 \mathrm{~m}$, following which communities are spatially independent of the mound. The sphere of influence around termite mounds was therefore considered to be greater at the wetter sites, extending to $4 \mathrm{~m}$ into the savanna matrix. When the landscape level sphere of direct influence of mounds was calculated at each site (using average mound diameter at each site, the magnitude of grass assemblage changes: $2 \mathrm{~m}$ at Skukuza and $4 \mathrm{~m}$ at both Napi and Pretoriuskop, and LiDAR data), mounds have a slightly larger direct effect at the wettest site, Pretoriuskop, where $2.37 \%$ of crest landscapes are directly affected. Although mounds had the largest sphere of influence at intermediate Napi, the overall landscape effect is smallest here due to lower mound densities, being $1.89 \%$ of the crest landscape. Skukuza (driest site) had intermediate landscape effects $(2.16 \%)$ because although mounds here are larger and occur at higher densities, the sphere of influence extends to only $2 \mathrm{~m}$ from mounds compared to $4 \mathrm{~m}$ at the wetter sites (Table 3).

Table 3: The area under direct influence (sphere of influence) around termite mounds with respect to change in grass communities. The mound densities from which the percentage figures are drawn are attained from LiDAR terrain data and reflect densities on crests within the landscape, the landscape percentage under direct influence subsequently refers to percentages of crests under direct influence. Sites are arranged in order of increasing mean annual precipitation; Skukuza receives $550 \mathrm{~mm} . \mathrm{yr}^{-1}$, Napi $625 \mathrm{~mm} . \mathrm{yr}^{-1}$ and Pretoriuskop $750 \mathrm{~mm} . \mathrm{yr}^{-1}$.

\begin{tabular}{|c|c|c|c|}
\hline Savanna site & $\begin{array}{l}\text { Sphere of influence } \\
\text { around mounds }\end{array}$ & density & $\begin{array}{l}\text { Mound Percentage of landscape } \\
\text { under direct influence }\end{array}$ \\
\hline Skukuza & $115.33 \mathrm{~m}^{2}$ & $1.87 \mathrm{ha}^{-1}$ & $2.16 \%$ \\
\hline Napi & $192.71 \mathrm{~m}^{2}$ & & $0.98 \mathrm{ha}^{-1}$ \\
\hline Pretoriuskop & $156.10 \mathrm{~m}^{2}$ & & $1.52 \mathrm{ha}^{-1}$ \\
\hline
\end{tabular}




\section{Discussion}

Our findings reveal that termite mounds are important agents of grass community assembly across varying savanna sites, acting as keystone structures that provide nutrient-rich patches of distinct grass species to those found in the savanna matrix. However, the effects of termite mounds on grass communities are not uniform across landscapes. Mounds have a greater influence on grass composition on wetter, nutrient-poor landscapes where differences between mound and savanna vegetation are more pronounced, with clearer thresholds of change in grass assemblages documented.

\section{Differences between mound and savanna matrix grasses}

Grass communities on termite mounds differed markedly from those in the savanna matrix across the rainfall gradient. At all three sites, grass species richness was greater in the savanna matrix, in contrast to documented patterns for woody plants and forbs (Loveridge \& Moe 2004; Traoré et al. 2008; Moe et al. 2009; Erpenbach et al. 2013). This finding concurs with Arshad (1982), while Moe et al. (2009) recorded no difference in grass species richness between mounds and the savanna matrix. It is well established that plant species richness follows a hump-shaped relationship along productivity gradients, with a peak at intermediate levels of productivity (Grime 1973; Mittelbach et al. 2001). Our findings suggest that for African savanna grasses, termite mounds represent areas of high productivity with species richness peaking at productivity levels lower than that of mounds. In temperate systems, grass species richness has been shown to peak in relatively nutrient-poor soils (Cornwell \& Grubb 2003), particularly where nitrogen and phosphorous levels are low (Crawley et al. 2005) and our results, along with those from east Africa (Arshad 1982; Moe et al. 2009), indicate that savanna grasses follow similar patterns. This pattern is consistent across the rainfall gradient, suggesting that the nutrient levels of termite mounds are consistently higher 
than optimal for grass species richness, possibly as a result of competitive exclusion leading to the dominance of a few species which monopolise the resource (Grime 1973). Moreover, since many savannas are nitrogen-limited environments due mostly to their frequent burning (Asner et al. 1997; Scholes 1997), it is likely that most grass species are adapted to nutrient levels lower than that of termite mounds.

Although the majority of studies that record plant biomass as a measure of productivity report a hump-shaped relationship between species richness and biomass, richness peaking at intermediate biomass levels (Mittelbach et al. 2001), neither standing biomass nor grass cover on and off termite mounds differed in our study at any site. Termite mounds act as focal feeding sites for both mammalian (Mobæk et al. 2005) and insect (Davies et al. in prep.) grazers in savanna systems, which likely leads to lower standing biomass and grass cover than would be expected in the absence of herbivores. Potential biomass (biomass in the absence of grazers) is therefore likely to be much higher than observed standing biomass on mounds.

The grass communities on termite mounds differed significantly from the savanna matrix vegetation, with very little overlap of species. Thus, although supporting fewer species than the savanna matrix, the species composition on mounds was almost entirely different, providing a distinct habitat to that of the more expansive savanna matrix. Similar high levels of dissimilarity between mounds and savanna matrix were recorded at all three sites, despite the grass communities at the wettest site being very different to those at the other two sites. Termite mounds therefore appear to play a consistent keystone role across ecosystem types by supporting different grass assemblages. Indeed, similar differences in grass assemblages have been recorded in various African (Arshad 1982; Jouquet et al. 2004) and Australian (Spain \& McIvor 1988) savannas. 
Grass species growing on mounds are highly nutritious with significantly lower C: N ratios than savanna matrix grasses, making assemblages distinct both taxonomically and functionally. Moreover, all species identified as characteristic of termite mounds (except Bothriochloa radicans) are highly nutritious and palatable to grazing animals (van Oudtshoorn 1999), and several are stoloniferous, forming grazing lawns under high grazing pressure (notably Cynodon dactylon and Urochloa mosambicensis), which are important forage patches for herbivore populations (Archibald 2008; Cromsigt \& Olff 2008). It is likely Bothriochloa radicans occurs on mounds because termite activity concentrates clay particles here (Jouquet et al. 2004), providing an ideal habitat for this species, which grows in soils with high clay content (van Oudtshoorn 1999). Savanna matrix soils in this system are generally sandy with low clay content (Venter 1990).

The ecological heterogeneity created by termites through mound construction thus plays a critical functional role in savannas through the provision of nutrient-rich grass patches which are favoured by herbivores (Mobæk et al. 2005, Davies et al. in prep.). Furthermore, Macrotermes mounds are predominantly located on nutrient-poor crests within this landscape (Levick et al. 2010a; Davies et al. 2014) and their presence here is likely to facilitate the persistence of herbivores in areas that represent marginal habitat and would be otherwise less suitable (Grant \& Scholes 2006).

\section{Spatial extent of termite influence}

In line with our reported patterns on and off termite mounds, grass species richness increased with distance from termite mounds, while cover and standing biomass exhibited mixed patterns with no clear threshold detected. Across the three sites, grass species richness was significantly higher at a distance of $4 \mathrm{~m}$ than on the mounds. However, the threshold for change in grass composition varies among sites. At the driest and most nutrient-rich site, 
Skukuza, the sphere of influence is smaller, extending only to $2 \mathrm{~m}$ from mounds, with grass community assemblages changing gradually with distance from termite mounds. As mean annual precipitation increases (and savanna vegetation becomes relatively nutrient-poor), differences become more pronounced and the sphere of influence around mounds increases to $4 \mathrm{~m}$. These findings support our predictions: mounds in wetter areas have a stronger effect on grass communities and clearer thresholds are detected.

The more distinct differences in grass assemblages detected at the wetter sites mirror the changes in the $\mathrm{C}$ : $\mathrm{N}$ ratio recorded from the grass samples. At these wetter sites there is a consistent, steep increase in $\mathrm{C}$ : $\mathrm{N}$ up to $4 \mathrm{~m}$ from mounds, after which the increase is more gradual to $16 \mathrm{~m}$, and then levels off beyond $16 \mathrm{~m}$ from the mound. In contrast, at the driest site Skukuza, the $\mathrm{C}$ : $\mathrm{N}$ ratio levels off after only about $2 \mathrm{~m}$. The lower $\mathrm{C}: \mathrm{N}$ ratio sustained in the drier, relatively nutrient-rich savanna mitigates the effect termite mounds have on grass assemblages, with nutrient-rich grasses persisting away from mounds. Indeed even some of the dominant grasses in the savanna matrix (e.g. Digitaria eriantha and Brachiaria nigropedata) not found on termite mounds are also nutritious and considered palatable (van Oudtshoorn 1999). Macrotermes mound soil provides an ideal environment for grazing lawn species such as those growing on the mounds themselves, and enhances their spread through erosion of mound soil to the matrix (Gosling et al. 2012). However, the environmental conditions (lower rainfall leading to lower denitrification and leaching) at the drier savanna site lessens this effect, allowing grasses with lower $\mathrm{C}$ : $\mathrm{N}$ to persist in the savanna matrix, resulting in gradual changes here and the sphere of influence to be smaller compared to that of the wetter sites, where this eroded material is more important for maintaining high nutrient availability for lawn grasses. Working in a relatively nutrient-rich savanna, van der Plas et al. (2013) found that trees off mounds are more favoured by browsers than those on mounds, in contrast to all previous studies relating browsing activity to termite mounds. They attribute 
this finding to the high nutrient value of the savanna matrix, which results in differences on and off mounds being reduced, and suggests that the importance of mounds as nutrient hotspots varies with landscape context. The gradual differences and smaller spheres of influence around termite mounds in the drier, savanna in our study indicate that similar context dependant processes are likely operating for grass communities in southern Africa.

The sphere of influence around termite mounds in relation to savanna grasses constitutes around 2\% of crest landscapes. In Uganda, Moe et al. (2009) report that termite mounds themselves occupy about $5 \%$ of the landscape, while Levick et al. (2010b) calculated the sphere of influence mounds have on browsing patterns to be as high as $20 \%$. The lower values that we found compared to east Africa may be attributed to lower mound densities recorded in southern Africa, but are also potentially more accurate due to the possibility of surveying larger areas with LiDAR compared to field-based studies, which could be focused on small areas with high mound densities (Davies et al. 2014). Although browsing extent around mounds is an order of magnitude greater (Levick et al. 2010b) than the influence mounds have on grasses, the effect on woody species assemblages is so far unknown, and here we do not report grazing influences of mounds (which would be more closely related to browsing) but rather grass species patterns. However, woody plants have deeper, more extensive root systems than grasses with their roots extending well beyond their own canopy (Scholes \& Archer 1997). It is likely that the larger rooting systems enable woody plants to access the nutrient and moisture enriched soil around termite mounds at greater distances than grasses, enlarging the sphere of influence that mounds have on browsing patterns and likely woody plants.

The sphere of influence measured in this study reflects the direct influence Macrotermes mounds have on grass communities; indirect ecosystem effects are likely to be larger. For example, grazing herbivores are attracted to mounds (Mobæk et al. 2005; Grant \& 
Scholes 2006) and such cascading effects induced by mounds are likely to be extensive. Furthermore, although only directly affecting around $2 \%$ of the landscape, $18 \%$ of the grass species recorded during this study occurred exclusively on or within the sphere of influence of termite mounds. These compositionally distinct grass assemblages increase overall savanna biodiversity and also differ functionally, providing hotspots of enhanced nutrition in otherwise nutrient-poor regions. Therefore, although termite mounds constitute a relatively small proportion of the savanna landscape, they are keystone structures that have a much greater influence on savanna structure and function than mound size alone would suggest.

\section{Acknowledgements}

We thank D. Knapp, T. Kennedy-Bowdoin and R. Martin for their contributions as members of the Carnegie Airborne Observatory as well as W. Matthews for initial help with grass identification. We are grateful for the excellent help I. Kuhlmann and I. Hilke provided with $\mathrm{C}$ and $\mathrm{N}$ analyses at the Max Planck Institute for Biogeochemistry. South African National Parks is thanked for logistical and scientific support and the DST-NRF Centre of Excellence for Invasion Biology and the South African National Parks/University of Pretoria Bursary Scheme for funding. Field work and application of the CAO data in South Africa is made possible by the Andrew Mellon Foundation, Grantham Foundation for the Protection of the Environment, and the endowment of the Carnegie Institution for Science. The Carnegie Airborne Observatory is supported by the Avatar Alliance Foundation, Gordon and Betty Moore Foundation, Grantham Foundation for the Protection of the Environment, W. M. Keck Foundation, the Margaret A. Cargill Foundation, Mary Anne Nyburg Baker and G. Leonard Baker Jr., and William R. Hearst III. 


\section{References}

Archibald, S. 2008. African Grazing Lawns-How Fire, Rainfall, and Grazer Numbers Interact to Affect Grass Community States. The Journal of Wildlife Management 72: 492-501.

Arshad, M.A. 1982. Influence of the termite Macrotermes michaelseni (Sjöst) on soil fertility and vegetation in a semi-arid savannah ecosystem. Agro-Ecosystems 8: 47-58.

Asner, G.P., Knapp, D.E., Kennedy-Bowdoin, T., Jones, M.O., Martin, R.E., Boardman, J. \& Field, C.B. 2007. Carnegie Airborne Observatory: in-flight fusion of hyperspectral imaging and waveform light detection and ranging for three-dimensional studies of ecosystems. Journal of Applied Remote Sensing 1: 013536-013536.

Asner, G.P., Seastedt, T.R. \& Townsend, A.R. 1997. The Decoupling of Terrestrial Carbon and Nitrogen Cycles. BioScience 47: 226-234.

Bond, W.J. \& Keeley, J.E. 2005. Fire as a global 'herbivore': the ecology and evolution of flammable ecosystems. Trends in Ecology \& Evolution 20: 387-394.

Borcard, D., Gillet, F. \& Legendre, P. 2011. Numerical Ecology with R. Springer, New York City.

Brody, A.K., Palmer, T.M., Fox-Dobbs, K. \& Doak, D.F. 2010. Termites, vertebrate herbivores, and the fruiting success of Acacia drepanolobium. Ecology 91: 399-407.

Clarke, K.R. \& Warwick, R.M. 2001. Change in Marine Communities: An Approach to Statistical Analysis and Interpretation. PRIMER-E, Plymouth, U.K.

Cornwell, W.K. \& Grubb, P.J. 2003. Regional and local patterns in plant species richness with respect to resource availability. Oikos 100: 417-428.

Crawley, M.J., Johnston, A.E., Silvertown, J., Dodd, M., de Mazancourt, C., Heard, M.S., Henman, D.F. \& Edwards, G.R. 2005. Determinants of Species Richness in the Park Grass Experiment. The American Naturalist 165: 179-192. 
Cromsigt, J.P.G.M. \& Olff, H. 2008. Dynamics of grazing lawn formation: an experimental test of the role of scale-dependent processes. Oikos 117: 1444-1452.

Dangerfield, J.M., McCarthy, T.S. \& Ellery, W.N. 1998. The mound-building termite Macrotermes michaelseni as an ecosystem engineer. Journal of Tropical Ecology 14: $507-520$.

Davies, A.B., Levick, S.R., Asner, G.P., Robertson, M.P., van Rensburg, B.J. \& Parr, C.L. 2014. Spatial variability and abiotic determinants of termite mounds throughout a savanna catchment. Ecography: DOI: 10.1111/ecog.00532.

du Toit, J.T. \& Cumming, D.H.M. 1999. Functional significance of ungulate diversity in African savannas and the ecological implications of the spread of pastoralism. Biodiversity and Conservation 8: 1643-1661.

Dufrêne, M. \& Legendre, P. 1997. Species assemblages and indicator species: the need for a flexible asymmetrical approach. Ecological Monographs 67: 345-366.

Erpenbach, A., Bernhardt-Römermann, M., Wittig, R., Thiombiano, A. \& Hahn, K. 2013. The influence of termite-induced heterogeneity on savanna vegetation along a climatic gradient in West Africa. Journal of Tropical Ecology 29: 11-23.

Gertenbach, W.P.D. 1983. Landscapes of the Kruger National Park. Koedoe 26: 9-121.

Gosling, C., Cromsigt, J., Mpanza, N. \& Olff, H. 2012. Effects of Erosion from Mounds of Different Termite Genera on Distinct Functional Grassland Types in an African Savannah. Ecosystems 15: 128-139.

Gotelli, N.J. \& Colwell, R.K. 2001. Quantifying biodiversity: procedures and pitfalls in the measurement and comparison of species richness. Ecology Letters 4: 379-391.

Grant, C.C. \& Scholes, M.C. 2006. The importance of nutrient hot-spots in the conservation and management of large wild mammalian herbivores in semi-arid savannas. Biological Conservation 130: 426-437. 
Grime, J.P. 1973. Competitive exclusion in herbaceous vegetation. Nature 242: 344-347.

Holdo, R.M. \& McDowell, L.R. 2004. Termite Mounds as Nutrient-Rich Food Patches for Elephants. Biotropica 36: 231-239.

Joseph, G.S., Seymour, C.L., Cumming, G.S., Cumming, D.H.M. \& Mahlangu, Z. 2013a. Termite mounds as islands: woody plant assemblages relative to termitarium size and soil properties. Journal of Vegetation Science 24: 702-711.

Joseph, G.S., Seymour, C.L., Cumming, G.S., Mahlangu, Z. \& Cumming, D.H.M. 2013 b. Escaping the flames: large termitaria as refugia from fire in miombo woodland. Landscape Ecology: 1-12.

Jouquet, P., Boulain, N., Gignoux, J. \& Lepage, M. 2004. Association between subterranean termites and grasses in a West African savanna: spatial pattern analysis shows a significant role for Odontotermes n. pauperans. Applied Soil Ecology 27: 99-107.

Jouquet, P., Tavernier, V., Abbadie, L. \& Lepage, M. 2005. Nests of subterranean fungusgrowing termites (Isoptera, Macrotermitinae) as nutrient patches for grasses in savannah ecosystems. African Journal of Ecology 43: 191-196.

Levick, S.R., Asner, G.P., Chadwick, O.A., Khomo, L.M., Rogers, K.H., Hartshorn, A.S., Kennedy-Bowdoin, T. \& Knapp, D.E. 2010a. Regional insight into savanna hydrogeomorphology from termite mounds. Nature Communications 1: 65.

Levick, S.R., Asner, G.P., Kennedy-Bowdoin, T. \& Knapp, D.E. 2010b. The spatial extent of termite influences on herbivore browsing in an African savanna. Biological Conservation 143: 2462-2467.

Loveridge, J.P. \& Moe, S.R. 2004. Termitaria as Browsing Hotspots for African Megaherbivores in Miombo Woodland. Journal of Tropical Ecology 20: 337-343. 
McGeoch, M.A., Van Rensburg, B.J. \& Botes, A. 2002. The verification and application of bioindicators: a case study of dung beetles in a savanna ecosystem. Journal of Applied Ecology 39: 661-672.

Mittelbach, G.G., Steiner, C.F., Scheiner, S.M., Gross, K.L., Reynolds, H.L., Waide, R.B., Willig, M.R., Dodson, S.I. \& Gough, L. 2001. What is the observed relationship between species richness and productivity? Ecology 82: 2381-2396.

Mobæk, R., Narmo, A.K. \& Moe, S.R. 2005. Termitaria are focal feeding sites for large ungulates in Lake Mburo National Park, Uganda. Journal of Zoology, London 267: 97-102.

Moe, S.R., Mobæk, R. \& Narmo, A.K. 2009. Mound building termites contribute to savanna vegetation heterogeneity. Plant Ecology 202: 31-40.

Okullo, P. \& Moe, S.R. 2012a. Large herbivores maintain termite-caused differences in herbaceous species diversity patterns. Ecology 93: 2095-2103.

Okullo, P. \& Moe, S.R. 2012b. Termite activity, not grazing, is the main determinant of spatial variation in savanna herbaceous vegetation. Journal of Ecology 100: 232-241.

R Development Core Team 2012. R: A Language and Environment for Statistical Computing. In. R Foundation for Statistical Computing, Vienna, Austria.

Scholes, R.J. 1997. Savanna. In: Cowling, R.M., Richardson, D.M. \& Pierce, S.M. (eds.) Vegetation of Southern Africa. Cambridge University Press, Cambridge.

Scholes, R.J. \& Archer, S.R. 1997. Tree-Grass Interactions in Savannas. Annual Review of Ecology and Systematics 28: 517-544.

Seymour, C.L., Milewski, A.V., Mills, A.J., Joseph, G.S., Cumming, G.S., Cumming, D.H.M. \& Mahlangu, Z. 2014. Do the large termite mounds of Macrotermes concentrate micronutrients in addition to macronutrients in nutrient-poor African savannas? Soil Biology and Biochemistry 68: 95-105. 
Sileshi, G.W. \& Arshad, M.A. 2012. Application of distance-decay models for inferences about termite mound-induced patterns in dryland ecosystems. Journal of Arid Environments 77: 138-148.

Sileshi, G.W., Arshad, M.A., Konaté, S. \& Nkunika, P.O.Y. 2010. Termite-induced heterogeneity in African savanna vegetation: mechanisms and patterns. Journal of Vegetation Science 21: 923-937.

Spain, A.V. \& McIvor, J.G. 1988. The Nature of Herbaceous Vegetation Associated with Termitaria in North- Eastern Australia. Journal of Ecology 76: 181-191.

Steinke, T.D. \& Nel, L.O. 1989. Some effects of termitaria on veld in the eastern Cape. Tydskrif Weidingsveren. S. Afr. 6: 152-155.

Traoré, S., Nygard, R., Guinko, S. \& Lepage, M. 2008. Impact of Macrotermes termitaria as a source of heterogeneity on tree diversity and structure in a Sudanian savanna under controlled grazing and annual prescribed fire (Burkina Faso). Forest Ecology and Management 255: 2337-2346.

Van der Plas, F., Howison, R., Reinders, J., Fokkema, W. \& Olff, H. 2013. Functional traits of trees on and off termite mounds: understanding the origin of biotically-driven heterogeneity in savannas. Journal of Vegetation Science 24: 227-238.

van Oudtshoorn, F. 1999. Guide to grasses of southern Africa. Briza, Pretoria.

Venter, F.J. 1990. A Classification of Land for Management Planning in the Kruger National Park. PhD Thesis, University of South Africa. 


\section{Appendix S1: Sampling design}

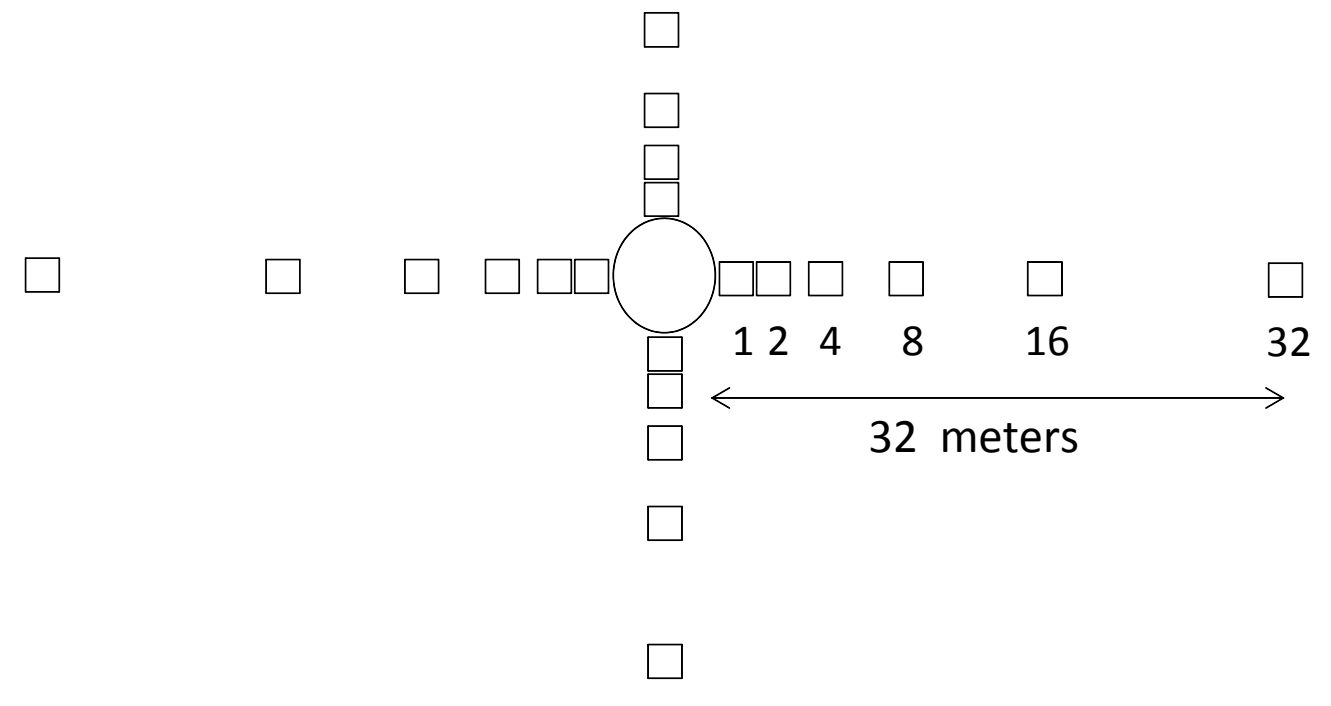

Figure S1: Schematic representation of the sampling employed for the grass survey transects. Four transects consisting of 1 x $1 \mathrm{~m}$ quadrats placed at set distance intervals $(1,2,4,8,16$ and $32 \mathrm{~m}$ ) were laid out from termite mounds in the four cardinal directions and the grasses occupying them surveyed. Grass and soil samples were also collected from each quadrat for nutrient analyses. 


\section{Appendix S2: Sampling adequacy}

Sampling adequacy of the grass surveyed on termite mounds and savanna plots was assessed using sample-based rarefaction curves and appropriate richness estimators (Gotelli \& Colwell 2001) using EstimateS software version 8.2 (http://viceroy.eeb.uconn.edu/estimates). If the observed rarefaction curve approaches an asymptote or converges closely with appropriate richness estimators at the highest observed species richness, sampling is considered to be adequate and representative of the studied assemblage (Gotelli \& Colwell 2001; Longino et al. 2002). In most cases, sampling was considered adequate and so observed data were used in subsequent analyses. The sampling at the wettest site, Pretoriuskop, was the least complete, but not considered to be grossly under-sampled. Moreover, sampling adequacy on termite mounds and savanna plots was relatively similar here (Figure S2). 

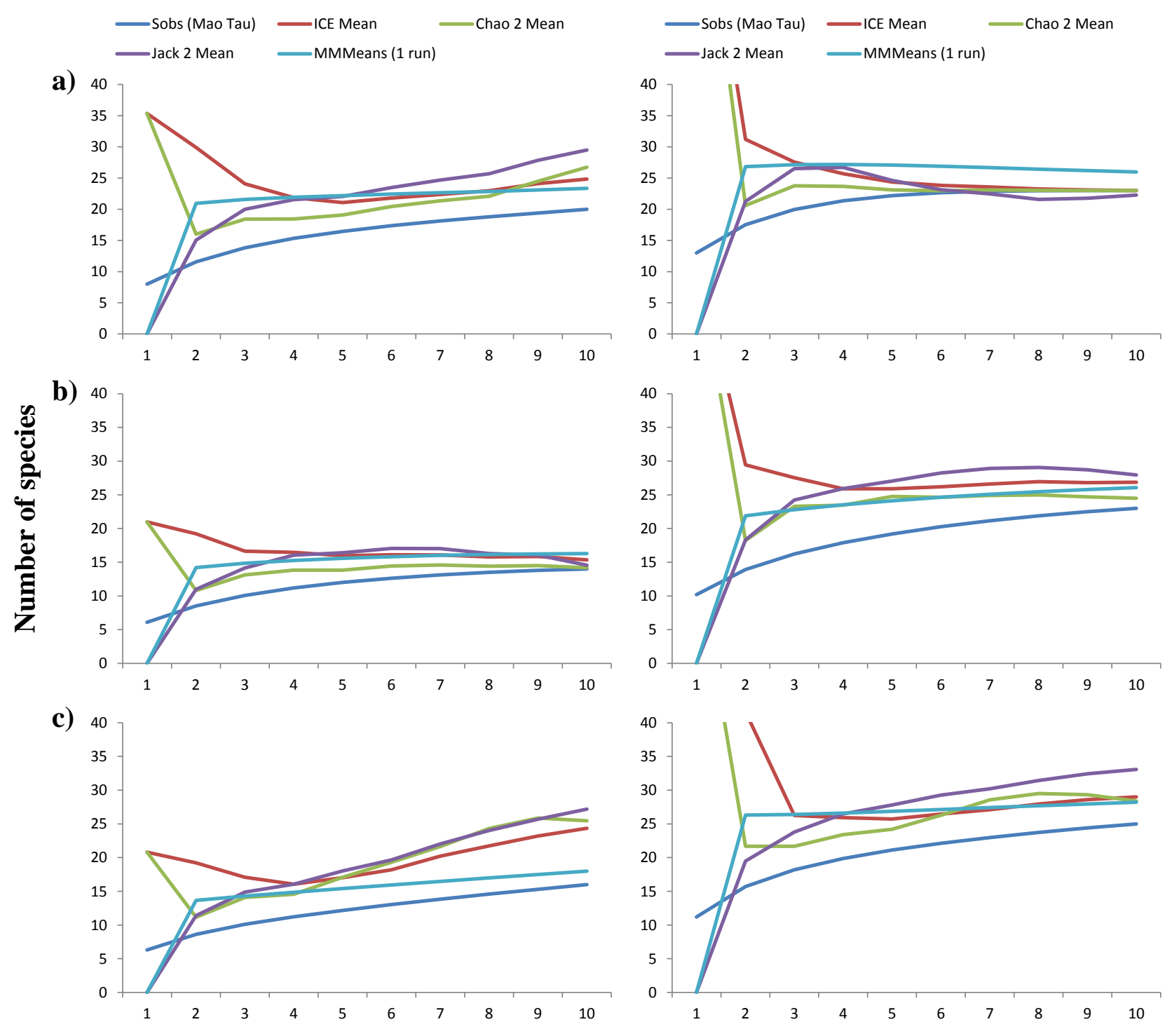

\section{Number of samples}

Figure S2: Sampled-based species rarefaction curves based on the observed number of species (S Obs) and richness estimators: ICE Mean, Chao 2 Mean, Jack 2 Mean and MM Means. The first column represents termite mounds while the second column represents savanna areas, for a) Skukuza, b) Napi and c) Pretoriuskop. 
Appendix S3: Grass species sampled on termite mounds and in the savanna matrix
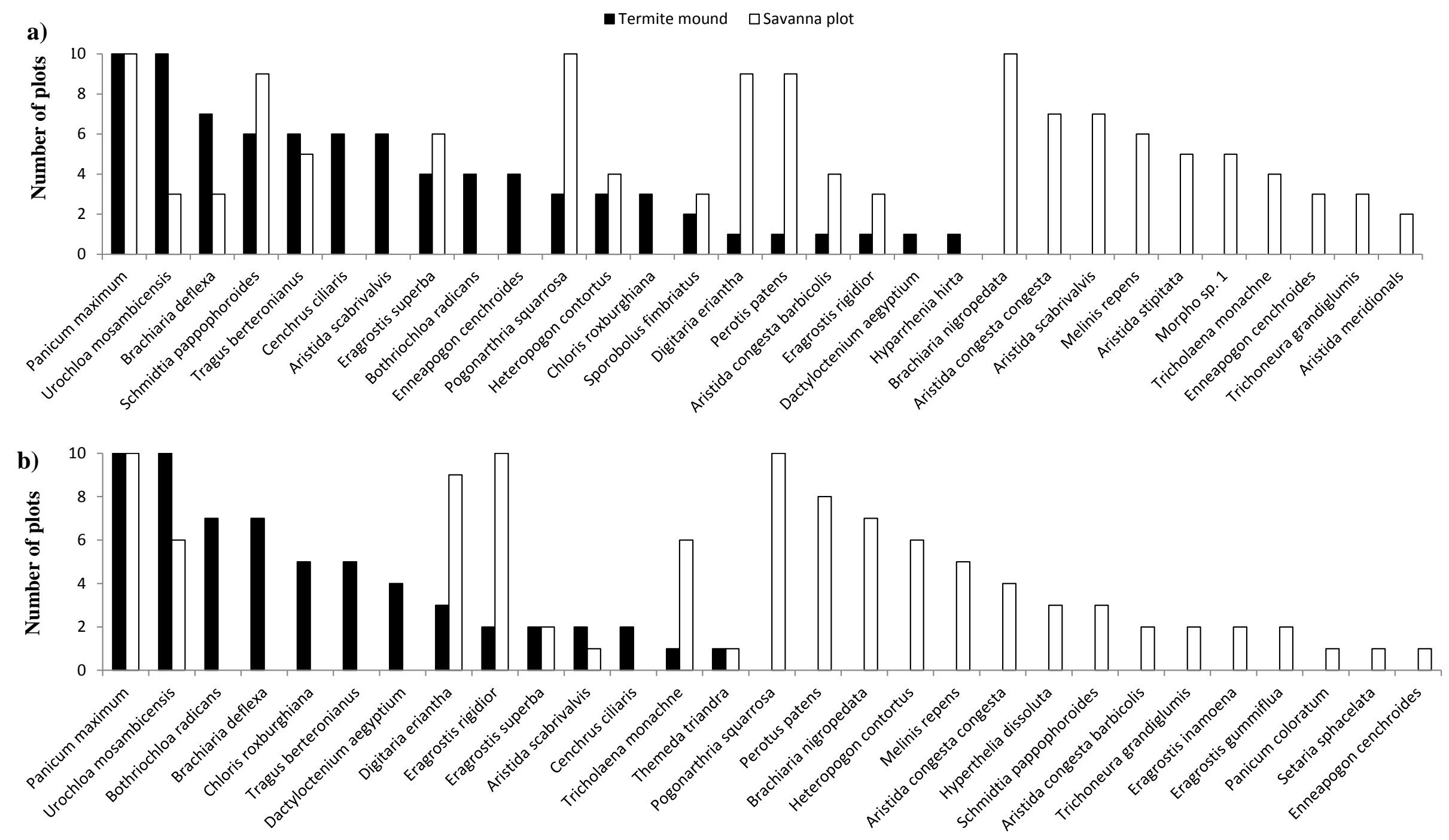
Appendix S4: Number of grass species, grass cover and standing biomass across distance transects from termite mounds

a)

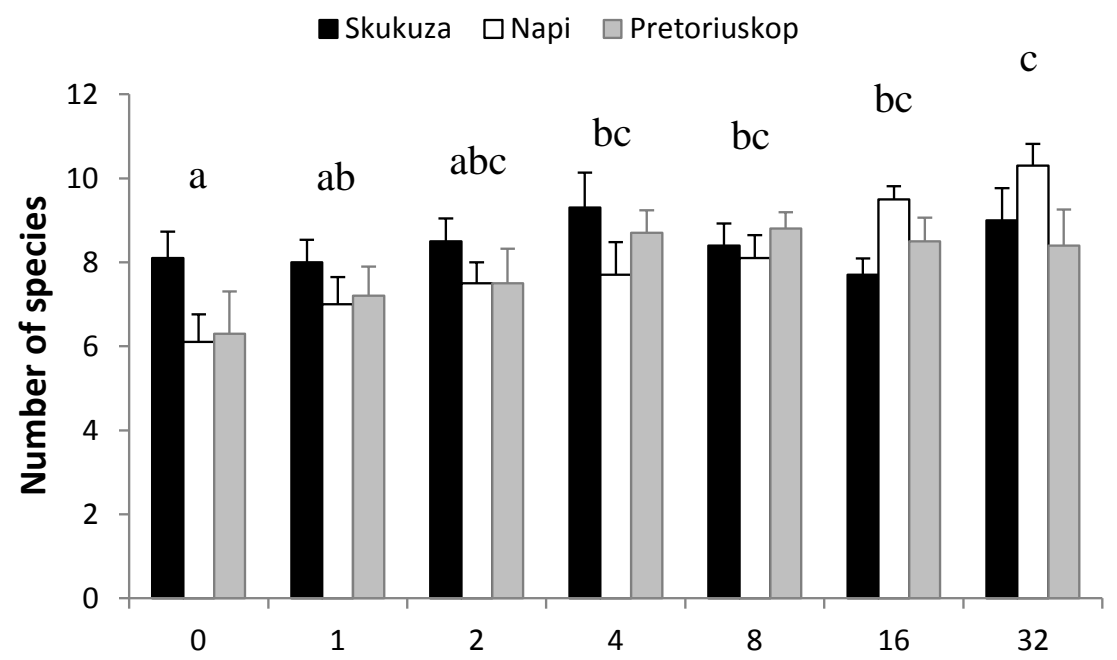

b)

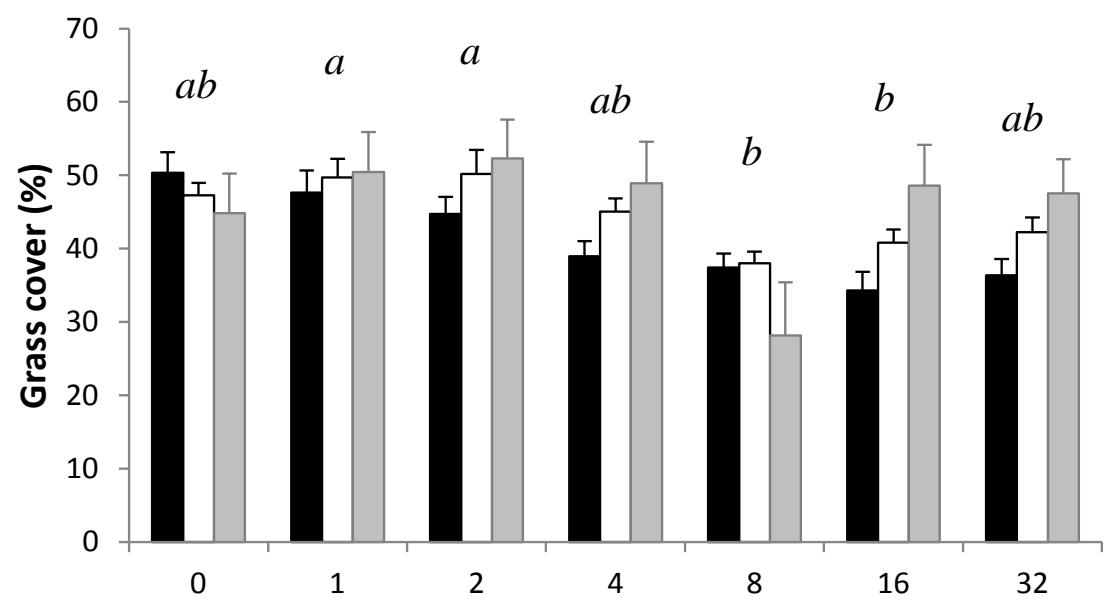

c)

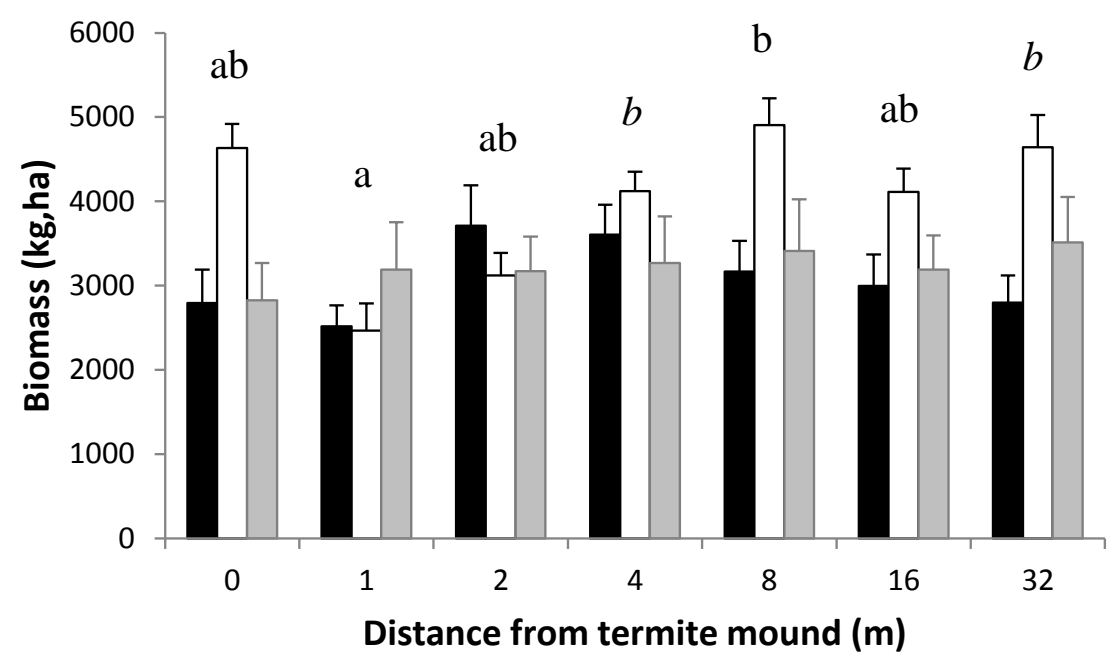


Figure S4: Grass species richness (a), percentage of cover (b) and standing biomass (c) along transects of increasing distance from termite mounds at three savanna sites situated across a rainfall gradient. Sites are arranged in order of increasing mean annual rainfall. Letters denote significant differences between distance classes $(\alpha=0.05)$, letters in italics denote differences at the alpha level of 0.1 and are included to show trends. 


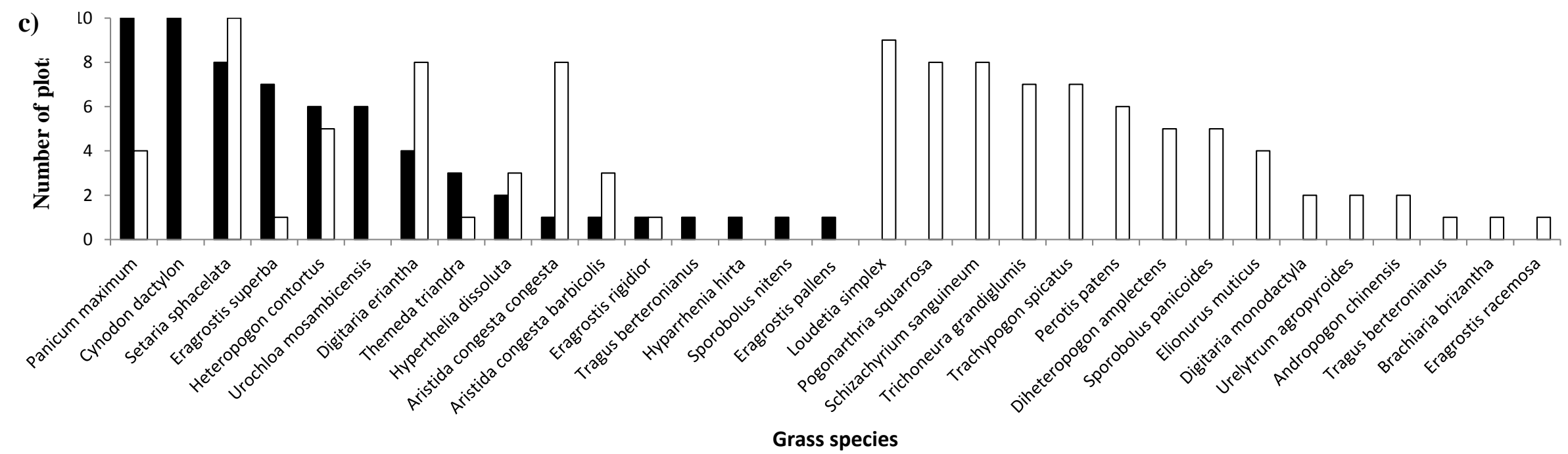

Figure S3: Number of mounds or savanna matrix plots $(\mathrm{n}=10$ for both) where a particular grass species was recorded at each of three savanna sites arranged in order of increasing mean annual rainfall, (a) Skukuza, (b) Napi and (c) Pretoriuskop. Species are ranked according to the frequency of their presence on mounds, i.e. the frequency of grass species on mounds decreases along the $\mathrm{x}$-axis. 